\title{
Modelling the cryogenic treatment of warts and recommendations for changes to current clinical practice
}

G. N. Mercer ${ }^{1}$

A. H. Tyson ${ }^{2}$

(Received 21 July 2008; revised 29 June 2009)

\begin{abstract}
Cryotherapy is a commonly used and recommended treatment for warts and there is wide variation in technique between clinicians applying the same mode of cryotherapy. To address this uncertainty in clinical practice a mathematical model is used to demonstrate the relationship between freezing time and tissue freezing zone for two commonly used cryogens (liquid nitrogen spray and nitrous oxide probes). It is found that nitrous oxide probes need substantially longer application time to obtain the same necrosis region as liquid nitrogen sprays. Overspray from liquid nitrogen spray is shown to lead to increased damage to healthy tissue surrounding a wart. Using a barrier of petrolatum (petroleum jelly) on the healthy tissue is demonstrated to be an effective means for limiting this damage. Changes to clinical practice to take account of these findings are recommended and need clinical trials to verify their applicability.
\end{abstract}

http://anziamj.austms.org.au/ojs/index.php/ANZIAMJ/article/view/1359 gives this article, (c) Austral. Mathematical Soc. 2009. Published July 10, 2009. ISSN 1446-8735. (Print two pages per sheet of paper.) 


\section{Contents}

1 Introduction

C977

2 Mathematical model

C978

3 Current treatment scenario results

C980

4 Effect of wart size

C982

5 Changes to clinical practice

C982

6 Conclusion

C987

References

C988

\section{Introduction}

Cryotherapy is a commonly used and recommended treatment for warts $[5,8]$. A variety of modes of application, recommended freeze times and interval between treatments are used $[2,9]$. Common recommendations are to create a 1-2 mm halo of frozen tissue around the wart and freeze for 5-30 seconds. Larger freeze times are associated with increased risk of pain and blistering [3]. Numerous texts suggest that the size of the wart determines the freeze time required without stating if this is the height, diameter or volume of the wart, or how the size and freeze time are related. There is wide variation in technique between clinicians applying the same mode of cryotherapy [8]. 


\begin{tabular}{|c|c|c|c|c|}
\hline$\rho$ & $C$ & $k$ & $\vdash 1-4 \mathrm{~mm} \multimap$ & \\
\hline $\mathrm{xgm}^{-3}$ & $\mathrm{Jkg}^{-1} \mathrm{~K}^{-1}$ & $\mathrm{Wm}^{-1} \mathrm{~K}^{-1}$ & & \\
\hline 1200 & 3600 & 0.24 & Epidermis & $0.08 \mathrm{~mm}$ \\
\hline 1200 & 3300 & 0.45 & Dermis & $1-2 \mathrm{~mm}$ \\
\hline 1000 & 2500 & 0.18 & Subcutaneous & $\geq 2 \mathrm{~mm}$ \\
\hline
\end{tabular}

Figure 1: Schematic of the layers and some of the physical parameters of the layers used in the model.

\section{Mathematical model}

To address this uncertainty in clinical practice a mathematical model is used to demonstrate the relationship between freezing time and tissue freezing zone for two commonly used cryogens (liquid nitrogen spray and nitrous oxide probes). In keeping with other skin heat transfer models $[6,7,10]$ the skin is assumed to consist of three layers (the epidermis, dermis and subcutaneous layers), see Figure 1. The thermal-physical properties are assumed constant within a skin layer but varying between layers and typical values used are also shown. Warts generally consist of epidermal cells and have thermal characteristics similar to the epidermis so these values are used for the wart as well. To simplify the analysis the wart is assumed to be circular in cross section thereby reducing the problem to the radial $(r)$ and depth $(z)$ dimensions only. Any circular symmetric shape can be studied. The one used here is shown in Figure 1.

The mathematical equation describes heat conduction through the skin and allows for the latent heat of fusion as the skin tissue freezes:

$$
\rho C \frac{\partial T}{\partial t}=\frac{\partial}{\partial z}\left(k \frac{\partial T}{\partial z}\right)+\frac{1}{r} \frac{\partial}{\partial r}\left(k r \frac{\partial T}{\partial r}\right)+\rho Q \frac{\partial S}{\partial t} .
$$


Here $\rho$ is the density $\left(\mathrm{kg} \mathrm{m}^{-3}\right), \mathrm{C}$ the specific heat $\left(\mathrm{J} \mathrm{kg}^{-1} \mathrm{~K}^{-1}\right)$, $\mathrm{T}$ the temperature $(\mathrm{K}), \mathrm{t}$ the time $(\mathrm{s}), \mathrm{k}$ the thermal conductivity $\left(\mathrm{W} \mathrm{m}^{-1} \mathrm{~K}^{-1}\right), \mathrm{Q}$ the heat of fusion $\left(\mathrm{J} \mathrm{kg}^{-1}\right)$ of the water in the skin tissue, $S$ is the solid ice fraction present in the skin ( $S=1$ is solid, $S=0$ is liquid). An explanation of the latent heat term in equation (1) was given by Mercer and Sidhu [7].

Equation (1) is solved with appropriate initial and boundary conditions using a time and space adaptive finite element package FlexPDE ${ }^{\mathrm{TM}}[4]$. Due to its adaptive nature both space and time errors are minimised and more mesh points are used in regions of large gradients such as at the skin surface and at the moving freezing line. All calculations are performed to a relative error tolerance of less than $0.1 \%$. FlexPDE has a cylindrical coordinate mode that enables the numerical solution to be two dimensional.

The initial temperature is a linear increase in temperature from $34^{\circ} \mathrm{C}$ at the skin surface to $37^{\circ} \mathrm{C}$ at the base of the subcutaneous layer. The radius of the computational zone is taken to be considerably larger than the region of influence of the cryogenic treatment so the boundary condition is a zero $r$ derivative. Due to blood perfusion through the subcutaneous layer the body maintains the base of the subcutaneous layer at the body core temperature of $37^{\circ} \mathrm{C}$ so this is taken as the lower boundary condition. For the sake of the numerical modelling the base of the subcutaneous layer is taken to be $10 \mathrm{~mm}$ below the skin surface but the precise value has little impact on the results. The skin surface boundary condition depends on the type of cryogenic treatment being modelled and the region of its influence. The boundary condition on the skin surface in the cryogen treatment zone is a heat flux onto the skin:

$$
h\left(T_{c}-T\right)=-k \frac{\partial T}{\partial n},
$$

where $n$ is the normal direction to the skin surface and $T_{c}$ is the cryogen temperature $\left(-190^{\circ} \mathrm{C}\right.$ for liquid nitrogen spray and $-90^{\circ} \mathrm{C}$ for nitrous oxide probes). The heat transfer coefficient $(h)$ depends on many factors such as the spray droplet size or the size and material of the probe. For liquid 
nitrogen spray $h$ is in the range $15-40 \mathrm{~kW} \mathrm{~m}^{-2} \mathrm{~K}^{-1}$ and for direct contact probes in the range $100-500 \mathrm{~kW} \mathrm{~m}^{-2} \mathrm{~K}^{-1}$ [1]. Away from the treatment zone (and after treatment has ceased) the boundary condition is Newtonian heat loss/gain to the ambient air of $20^{\circ} \mathrm{C}$ with a heat transfer coefficient of $h=$ $5 \mathrm{~W} \mathrm{~m}^{-2} \mathrm{~K}^{-1}[1]$.

\section{Current treatment scenario results}

Figure 2 shows the results from the scenario of a continuous spray application of liquid nitrogen over the entire wart surface and including a $2 \mathrm{~mm}$ margin around the wart. The $2 \mathrm{~mm}$ margin is common practice and traditionally thought to be necessary to ensure wart necrosis but we are unaware of any tests of this widely held belief. The tissue freeze line is shown as the dashed line. The cryogen was applied for 20 seconds which is in the range of normal application. The aim of the cryogenic treatment is for the tissue freeze line to reach the base of the dermis below the centre of the wart. This ensures that tissue necrosis leads to the destruction of the entire wart and there are no wart virus cells left viable to regrow. In achieving this degree of tissue freezing using liquid nitrogen spray there is deep tissue damage to the skin surrounding the wart. Clinically, this tissue damage leads to increased chance of scar formation, increased pain and longer recovery times.

In contrast to liquid nitrogen sprays, nitrous oxide probes are placed in direct contact with the wart upper surface. By being in direct contact there is less damage to the surrounding healthy tissue as overspray is eliminated. The direct contact increases the thermal transfer to the wart from the cryogen but the nitrous oxide is at a substantially warmer temperature $\left(-90^{\circ} \mathrm{C}\right)$ compared to the liquid nitrogen spray $\left(-190^{\circ} \mathrm{C}\right)$. The results from modelling this scenario are also shown in Figure 2. The probe was applied for 40 seconds which is at the upper end of what is considered normal clinical practice. This period of time was necessary to obtain approximately the same level of freezing at the centre of the wart. There is far less damage to the skin 


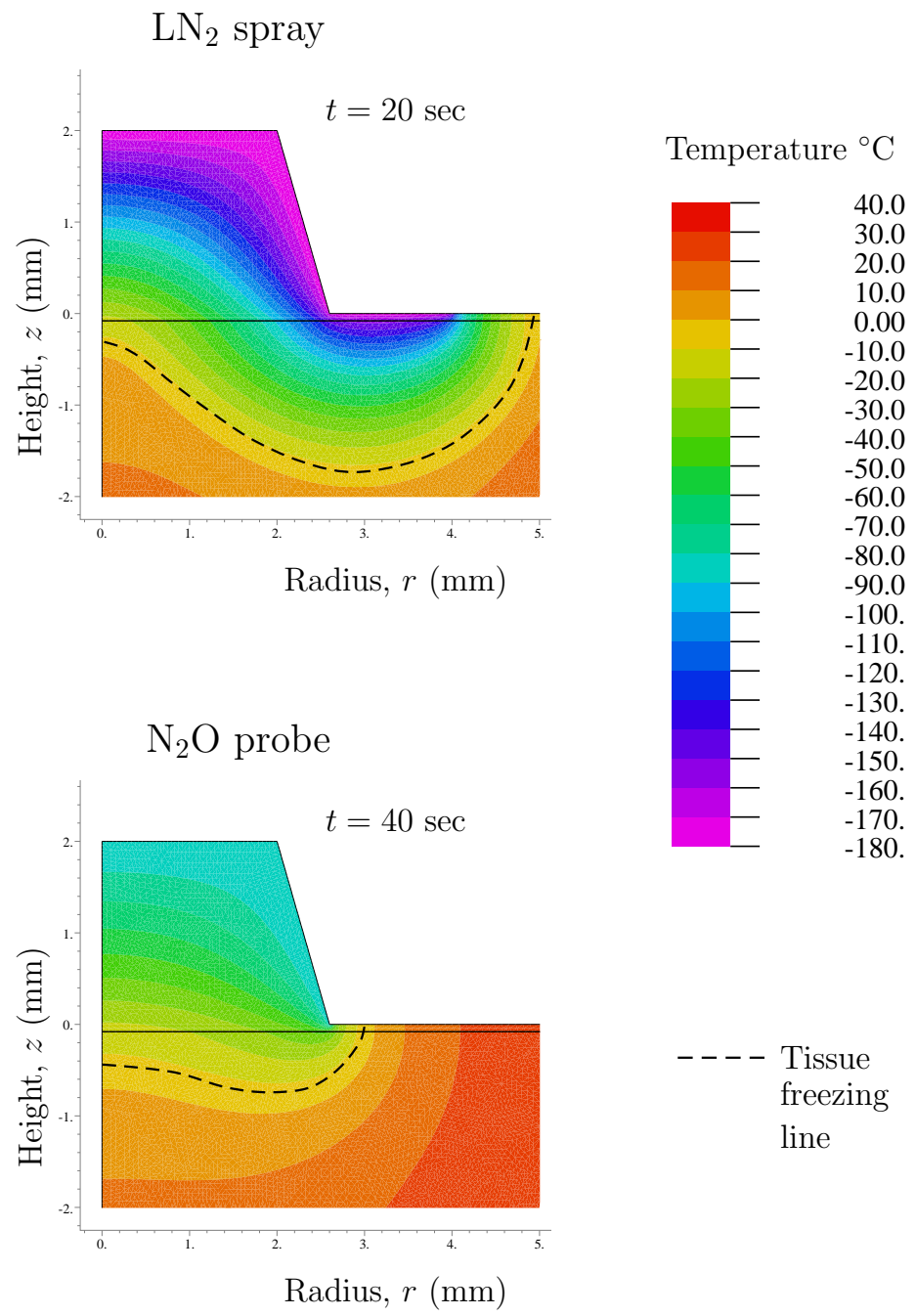

Figure 2: Temperature contours in the skin for a continuous liquid nitrogen spray on the wart and a $2 \mathrm{~mm}$ margin for a freeze time of 20 seconds (upper) and for a 40 second application of the nitrous oxide probe (lower). The tissue freeze line is the dashed line. 
around the wart with the freezing localised to the area in and below the wart compared to the liquid nitrogen method.

\section{Effect of wart size}

There are numerous references in the literature and clinical recommendations that the size of the wart determines the freeze time required but none of these detail what is meant by size of the wart. Our numerical experiments have concluded that the radius of the wart has virtually no effect on the length of freezing time required to reach necrosis at the centre of the wart. The dominant factor that affects freezing time is found to be the height of the wart. The size of the wart and its impact on freezing time is addressed in Figure 3. This is a plot of the time taken to achieve freezing at two positions below the centre of the wart (at the base of the epidermis and $1 \mathrm{~mm}$ below the epidermis) versus the height of the wart. Both liquid nitrogen spray and nitrous oxide probes are considered. The numerical results shown in Figure 3 demonstrate that when using nitrous oxide probes substantially longer cryogen application times than currently used in clinical practice are warranted.

\section{Changes to clinical practice}

In an attempt to reduce the damage caused by overspray when using liquid nitrogen sprays two barrier methods are considered. To be effective in a clinical setting any methods used must be easy to administer, use materials commonly found in the clinic and be relatively low cost as wart removal is a very common procedure. They must also be sterile and benign to the skin tissue both before and after the cryogenic treatment.

The first method consists of shielding the region around the wart with a solid 


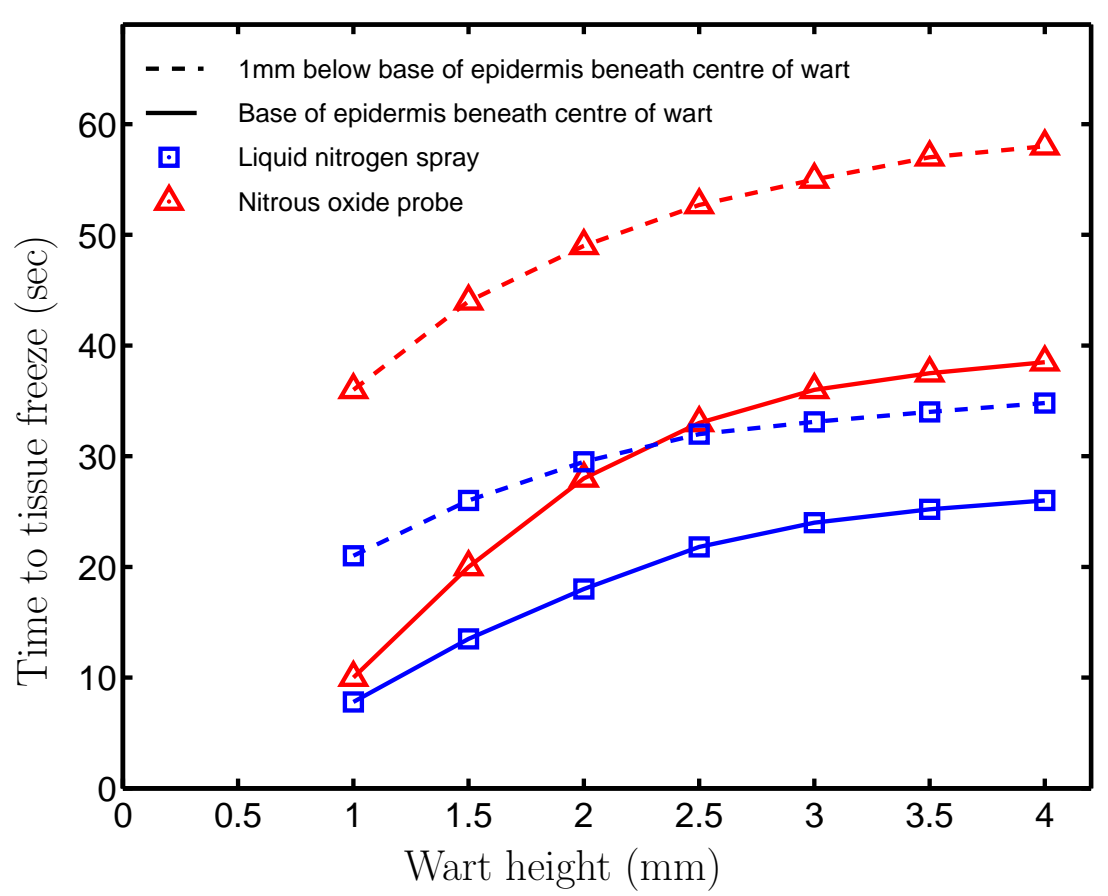

FiguRE 3: Time to tissue freezing versus wart height at two positions beneath the centre of a $2 \mathrm{~mm}$ radius wart. 


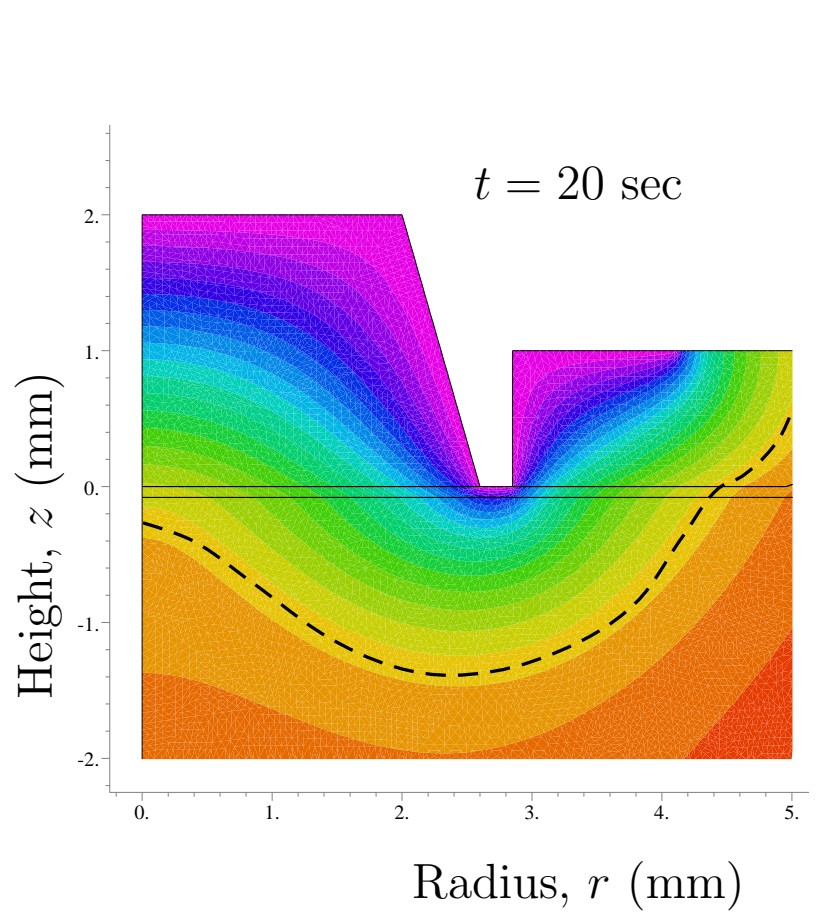

\section{Temperature ${ }^{\circ} \mathrm{C}$}

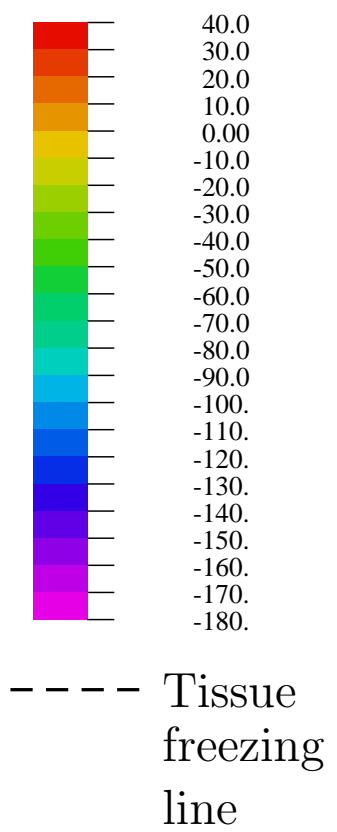

Figure 4: Temperature contours in the skin for a continuous liquid nitrogen spray on the wart for a freeze time of 20 seconds with a solid barrier of thick card placed around the wart. 
barrier such as thick card with holes punched through of the approximate size and shape of the wart. Due to the uneven nature of warts it is difficult to cut the hole in the card to exactly match the wart shape and so there is always a small gap between the card and wart. Of interest is how this gap impacts on the effectiveness of the barrier at reducing overspray induced tissue damage. Results from simulating this scenario with a $0.5 \mathrm{~mm}$ gap between the wart and the $1 \mathrm{~mm}$ thick card are shown in Figure 4. A relatively tight tolerance of $0.5 \mathrm{~mm}$ between the wart and card still results in considerable healthy tissue damage and so this method is considered not suitable. In addition, it is difficult to administer as holding the card in place requires additional personnel which is not effective use of resources. The card could be taped into place but this is an extra time consuming step in the process that practitioners are reluctant to undertake. The card was taken to have physical properties of $\rho=690 \mathrm{~kg} \mathrm{~m}^{-3}, \mathrm{C}=1340 \mathrm{~J} \mathrm{~kg}^{-1} \mathrm{~K}^{-1}$ and $\mathrm{k}=0.2 \mathrm{~W} \mathrm{~m}^{-1} \mathrm{~K}^{-1}$.

The second method is to use a flexible barrier. We choose petrolatum, commonly known as petroleum jelly. Although there are other products with better thermal characteristics than petrolatum, petrolatum was chosen as it is inexpensive and commonly found in the clinic. Petrolatum is smeared over the healthy tissue and importantly on the sides of the wart. The thicker the application the better protection afforded to the healthy tissue. Figure 5 show results of one scenario of a $1 \mathrm{~mm}$ thick layer of petrolatum surrounding a $2 \mathrm{~mm}$ high wart. The liquid nitrogen spray was applied for 20 seconds to be consistent with previous scenarios shown in Figures 2 and 4 . The petrolatum was taken to have physical properties of $\rho=900 \mathrm{~kg} \mathrm{~m}^{-3}, \mathrm{C}=2500 \mathrm{~J} \mathrm{~kg}^{-1} \mathrm{~K}^{-1}$ and $\mathrm{k}=0.25 \mathrm{~W} \mathrm{~m}^{-1} \mathrm{~K}^{-1}$.

The effect of the petrolatum is to reduce the damage to the healthy tissue by restricting the cooling of the healthy tissue surrounding the wart. The thicker the layer of petrolatum the better the outcome. The radial extent of the freeze line is only marginally affected by the petrolatum layer but the depth of the damage to the healthy tissue is greatly reduced by using the petrolatum. The petrolatum layer slows the cooling of the area immediately below the wart so the cryogen treatment needs to be applied for approximately $10 \%$ longer 


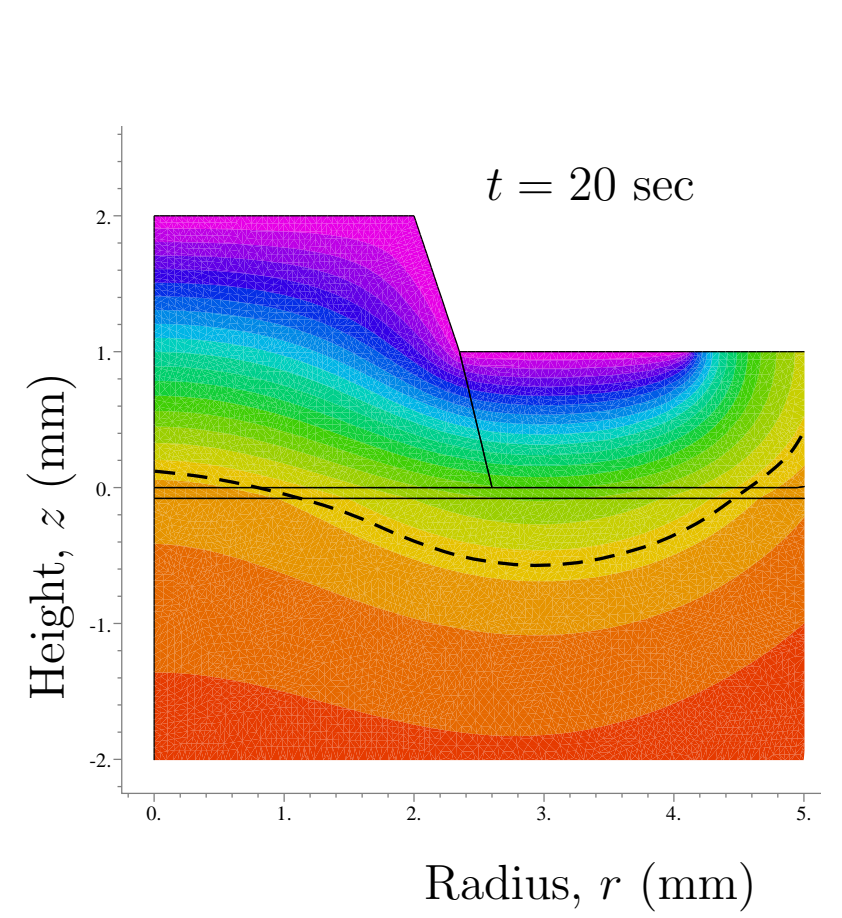

\section{Temperature ${ }^{\circ} \mathrm{C}$}

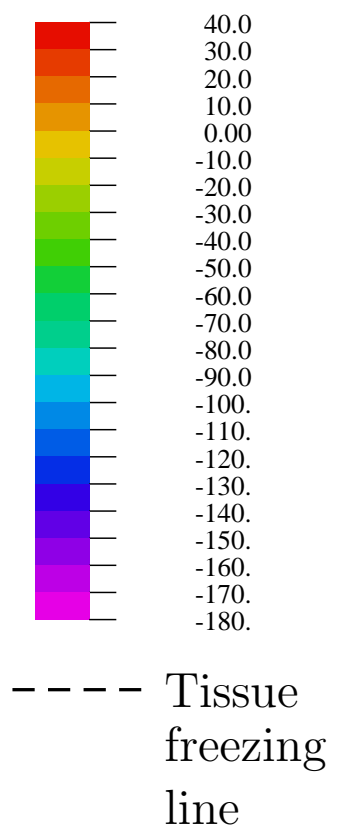

FiguRE 5: Temperature contours in the skin for a continuous liquid nitrogen spray on the wart for a freeze time of 20 seconds with a flexible barrier of petrolatum placed around the wart. 
than for the case without the barrier to obtain the same degree of freezing below the centre of the wart.

\section{Conclusion}

We developed a mathematical model to investigate two common cryotherapy treatments of warts. The difference in efficacy of the two commonly used methods needs to be taken into account when assessing the application time of the cryogen. In particular, nitrous oxide probes must have a longer application time than liquid nitrogen spray to obtain similar results.

A confounding factor in the use of liquid nitrogen sprays is the overspray which damages healthy tissue near the wart during treatment. We investigated two barrier methods to reduce the effect of this overspray. Rigid card is unsuitable both from a clinical perspective in terms of ease of use and also thermally as it is difficult to fit the card to the wart shape to provide adequate thermal protection. Applying a barrier of petrolatum (petroleum jelly) is a low cost, simple and effective means of reducing the damage to the healthy tissue surrounding the wart. The petrolatum needs to be applied as thickly as practical around the wart and on the sides of the wart but not on the upper surface of the wart.

The results presented here give a guide to possible changes to clinical practice that are simple to implement and may make a substantial difference to the outcome of cryogenic treatment of warts. The recommendations of increased treatment time for nitrous oxide probes and the use of flexible barriers to prevent overspray damage now need to be tested in the clinical setting. 


\section{References}

[1] G. Aguilar, W. Verkruysse, B. Majaron, L. O. Svaasand, E. J. Lavernia, and J. S. Nelson. Measurement of heat flux and heat transfer coefficient during continuous cryogen spray cooling for laser dermatologic surgery. J. on Selected Topics in Quantum Elect., 7:1013-1021, 2001. doi:10.1109/2944.983307. C980

[2] Anonymous. Clinical effectiveness group: National guidelines for the management of anogenital warts.

http://www. bashh.org/documents/86/86.pdf. C977

[3] M. Connolly, K. Bazmi, M. O'Connell, J. F. Lyons, and J F. Bourke. Cryotherapy of viral warts: a sustained 10-s freeze is more effective than the traditional method. Brit. J. Derm., 145:554-557, 2001. doi:10.1046/j.1365-2133.2001.04449.x. C977

[4] FlexPDE ${ }^{\mathrm{TM}}$. http://www.pdesolutions. com. C979

[5] H. McClean and S. Shann. A cross-sectional survey of treatment choices for anogenital warts. Int. J. STD \& AIDS, 16:212-216, 2005. doi:10.1258/0956462053420130. C977

[6] G. N. Mercer and H. S. Sidhu. A heat transfer model describing burns to the skin from automotive airbags. In Andrew Stacey, Bill Blyth, John Shepherd, and A. J. Roberts, editors, Proceedings of the 7th Biennial Engineering Mathematics and Applications Conference, EMAC-2005, volume 47 of ANZIAM J., pages C339-C354, October 2006. http://anziamj . austms.org.au/V47EMAC2005/Mercer [October 3, 2006]. C978

[7] G. N. Mercer and H. S. Sidhu. Mathematical modelling of the effect of fire exposure on a new type of protective clothing. In Geoffry N. Mercer and A. J. Roberts, editors, Proceedings of the 8th Biennial Engineering Mathematics and Applications Conference, EMAC-2007, 
volume 49 of ANZIAM J., pages C289-C305, January 2008.

http://anziamj. austms.org.au/ojs/index.php/ANZIAMJ/article/ view/346 [January 8, 2008]. C978, C979

[8] J. Sherrard and L. Riddell. Comparison of the effectiveness of commonly used clinic-based treatments for external genital warts. Int. J. STD \& AIDS, 18:365-368, 2007. doi:10.1258/095646207781024711. $\mathrm{C} 977$

[9] J.C. Sterling, S. Handfield-Jones, and P. M. Hudson. Guidelines for the management of cutaneous warts. Brit. J. Derm., 144:4-11, 2001. doi:10.1046/j.1365-2133.2001.04066.x. C977

[10] D. A. Torvi and J. D. Dale. A finite element model of skin subjected to a flash fire. J. Biomechanical Eng., 116:250-255, 1994. C978

\section{Author addresses}

1. G. N. Mercer, National Centre for Epidemiology and Population Health, Australian National University, Canberra, ACT 0200, Australia.

mailto:Geoff.Mercer@anu.edu . au

2. A. H. Tyson, Canberra Sexual Health Centre, Canberra Hospital, ACT, Australia. 